\title{
Altyapı Organizasyonlarının Futbolcu Yetiştirme Verimliliğgi Üzerine Bir İnceleme: Beşiktaş JK Örneği
}

\author{
Cengiz ÇOKPARTAL ${ }^{1 * i D}$, İ. Fatih YENEL ${ }^{2}$ iD \\ ${ }^{1}$ Karabük Üniversitesi, Sosyal Bilimler Meslek Yüksekokulu, Karabük, Türkiye \\ ${ }^{2}$ Gazi Üniversitesi, Spor Bilimleri Fakültesi, Ankara, Türkiye
}

Orijinal Makale

Gönderi Tarihi: 12.05.2021
Kabul Tarihi: 30.06 .2021
DOI: $10.47778 /$ ejsse.936836

Online Yayın: 30.06.2021

\section{$\ddot{\mathbf{O} z}$}

Bu çalışma, Beşiktaş JK futbol takımının 1999/2000 - 2019/2020 arasındaki sezonlarda altyapıdan oyuncu yetiştirme verimliliğini belirlemek üzere yapılmıştır. Araştırma, nitel araştırma yöntemlerinden durum çalışması modeli ve doküman analizi yöntemi kullanılarak gerçekleştirilmiştir. Elde edilen bulgular, 21 sezon incelendiğinde Beşiktaş JK futbol takımının toplam 69 oyuncuya A takım kadrosunda yer verdiğini göstermektedir. Bu oyunculardan sadece 5'inin 50 maç ve üzeri ilk 11'de oynama şansı bulduğu, 33 oyuncunun ise ilk 11 'de hiç yer almadığ 1 tespit edilmiştir. İlk 11 'de oynayan bu 5 futbolcunun oyunda kalma süresi, gol ve asist bakımından takıma katkı sağladıkları tespit edilmiştir. Bununla birlikte, altyapıdan yetişen 5 futbolcunun satışından 18 milyon 525 bin Avro transfer geliri elde edilirken, toplam 21 sezonda 104 yabancı futbolcuya 177 milyon 530 bin Avro transfer ücreti ödendiği belirlenmiştir. Sonuç olarak, incelenen sezonlarda Beşiktaş JK futbol takımının altyapıdaki oyunculardan yeterli düzeyde verim elde edemediği söylenebilir. Ancak firsat verildiğinde, A takımda oynama şansı bulan oyuncuların takıma sportif ve finansal açıdan katkı sağladıkları görülmektedir.

Anahtar kelimeler: Futbol, Altyap1, Verimlilik, Beşiktaş JK.

\section{Study on Efficiency of Youth Academy Organizations in Raising Players: Sample of Beşiktaş JK}

\begin{abstract}
This study was done to determine the efficiency of Beşiktaş JK football club in raising players from football youth academy. The research was carried out using case study model and document analysis method. Obtained data demonstrates that Beşiktaş football club included 69 players in first team squad totally when 21 seasons were examined. It was found out that 5 of these 69 players had chance to appear in line up of the matches 50 times or more whereas 33 of them had no appearance in line up of the matches. Contribution of these 5 players to the team in terms of goal, asist and duration of appearance hes been determined. Moreover, it was determined that the club earned 18 million 525 thousand Euros transfer income from 5 of these players while 177 million 530 thousand Euros was paid for foreign players in the same 21 seasons. In conclusion, it can be put forward that Beşiktaş football club was not able to obtain enough efficiency from youth academy. However, it is clearly seen that players from youth academy can contribute to the team in terms of financial and sportive performance when they have chance to perform.
\end{abstract}

Keywords: Football, Youth Academy, Efficiency, Beşiktaş JK.

\footnotetext{
* Sorumlu Yazar: Cengiz ÇOKPARTAL, E-posta: ccokpartal@ hotmail.com
} 


\section{GíRiş}

19. yüzyılın ikinci yarısında kurumsallaşarak tüm Avrupa'ya yayılan futbolun beşiği İngiltere olarak kabul edilir. 1863 yılında İngiliz Futbol Federasyonu'nun kurulması ile birlikte genişleme hızını artıran futbol seyahat eden İngiliz diplomat, aristokrat ve askerler tarafindan Avrupa'ya yayılarak 1904 yılında uzun adı Fédération Internationale de Football Association olan FíFA'nın kurulması ile birlikte kurumsallaşma sürecini devam ettirmiştir (TKYD, 2009: 14). Türkiye'nin futbolla tanışması ise 20. yüzyılın ilk yıllarında gerçekleşmiştir. Osmanlı İmparatorluğu döneminde 17 Mayıs 1903 yılında kurulan İstanbul Futbol Birliği ilk futbol örgütü olup, sırasıyla İstanbul Futbol Kulüpler Ligi, Cuma Ligi gibi teşkilatlanmalar futbolun organize edilmesi adına ilk yapılanmalar olmuştur (Yenel ve Parasız, 2019: 311). Daha sonraki süreçte, ilk Türkiye Futbol Federasyonu 1923 yılında 'Futbol Heyet-i Müttehidesi' adıyla kurularak aynı yıl FİFA'nın 26. üyesi olmuştur. Takip eden yıllarda 1952 yılında profesyonel statünün kabul edilmesi, 1954 yılında İsviçre'de düzenlenen futbol Dünya Kupası'na ilk kez katılım ve 1959 yılında şimdiki adı Süper Lig olan Türkiye 1. Futbol Ligi’nin kurulması futbolun yaygınlaşması ve gelişmesi adına önemli adımlar olmuştur (Türkiye Futbol Federasyonu, 2021a).

Milenyum çağı ile birlikte futbol bütün kitlelerin takip ettiği küresel bir olgu haline gelmiştir. Popüler olan, toplumlara mal olmuş, coşkulu halkları fetheden ve engel tanımaz olan futbol imparatorluğundan daha küresel bir olgu yoktur (Bonifance, 2007: 9). Bu çerçevede futbol, bir asırlık süreçte ülkeler arasındaki politika, din ve dil farklılıklarının göz ardı edilmesini sağlayarak küreselleşen dünyayı saran ortak bir tutku ve rekabete dönüşmüş ve modern futbol süreciyle birlikte belli bir kültür ya da kesime ait oyun olmaktan çıkarak kitleleri peşinden sürükleyen popüler bir eğlence aracı haline gelmiştir (Hünerli, 2014: 322). Özellikle 1990'l1 yılların başı bu süreçte önem arz etmektedir. 1992 yılında oynanmaya başlanan ve önemli bir ekonomik pazar oluşturan UEFA Şampiyonlar Ligi, futbolun endüstriyel sürece evrilmesinde bir mihenk taşı olarak futbol kulüplerini sadece bir sportif organizasyon değil aynı zamanda ekonomik organizasyonlara dönüştürmüştür (TKYD, 2009: 14). Bu bağlamda kulüplerin yayın, gişe, sponsorluk, lisanslı ürün ve transfer gibi önemli gelir kalemleri ortaya çıkmıştır. Bu anlamda transferleri hem bir gelir hem de bir gider unsuru olarak görmekte fayda olacaktır. Bu devasa büyüklükteki futbol pazarı içerisinde transferler ekonomik pastanın önemli bir unsurudur (Katırc1, 2019: 13). Kulüpler, Şampiyonlar Ligi organizasyonlarda boy göstererek hem ekonomik olarak kendilerine gelir kaynakları yaratmak hem de popülaritelerini artırmak istemektedirler. Ancak bu arenada büyük gelir elde edebilmek ve tutunabilmek için kaliteli kadrolar oluşturmak gereklidir. Dolayısıyla kulüpler büyük paralar harcayarak başarı ve beraberinde gelir getirecek kadro kurma çabası içerisine girmektedirler. Yapılan büyük transfer harcamaları beraberinde ekonomik riskleri de getirmektedir. Turnuvadan erken elenme ya da hiç katılamama durumu felaketi getirmiş olacak ve yapılan harcamaların geri dönüşünü mümkün kılmayacaktır (Bonifance, 2007: 153).

Türkiye'de futbol kulüpleri bahsedilen ekonomik pazardan pay alabilmek ve sportif başarıyı elde etmek adına transferlere büyük paralar harcamışlardır. Yapılan araştırmada Süper Lig'in en pahalı 50 transferine bakıldığında, dört büyükler olarak adlandırılan Fenerbahçe, Galatasaray, Beşiktaş 
JK ve Trabzonspor büyük bir kısmı yabancı futbolcu olmak üzere bu transferler için toplam 401 milyon Avro harcamıştır. En büyük harcamayı yapan Fenerbahçe 27 futbolcu için 214,3 milyon Avro, Galatasaray 16 futbolcu için 139,3 milyon Avro, Beşiktaş JK 5 futbolcu için 34,3 milyon Avro ve Trabzonspor en pahalılar listesinde bulunan iki futbolcu için13,1 milyon Avro transfer harcaması yapmıştır (Goal, 2021a). Mevcut liste en pahalı 50 futbolcuyu kapsadığı için, belirtilen dört büyük kulüp bu liste dışındaki futbolcular için de önemli miktarlarda transfer harcaması yaptılar. Ancak sportif başarısızlıklar, takıma adaptasyon sorunu ve sakatlıklar gibi nedenler bu transferlerden beklenen ekonomik katkı ve sportif verimin elde edilmesini engellemiştir. Transfere harcanan büyük meblağlar neticesinde, mevcut durumun en büyük kanıtı olarak bu dört büyük kulübün içinde bulunduğu mali krizler gösterilebilir. Deloitte'ın 26 Ocak 2021 tarihinde yayınlanan raporuna göre, 4 büyük kulübün toplam borcu 2020 yılında zirve yaparak 13 milyar TL'yi aşmıştır. Bu durum kulüplerin finansal fair play çerçevesinde hareket etmesini zorunlu kılarak limitler dahilinde transferler yapılmasını mecbur kılmıştır. Limitlerin az olması ve transfer yasakları kulüplerin istedikleri kadroları kurmalarına engel olarak yeni çözümler üretmelerini teşvik etmiştir. Yaşanan bu kriz ortamı kulüplerin öz kaynakları bir başka deyişle altyapıları ile ilgili gelecek planlamalarını özendirmiştir. Dolayısıyla, ekonomik anlamda büyük bir pazar olan futbol sektöründe pahalı transferlere büyük meblağlar ödemek yerine, kulüplerin kendi altyapıdan oyuncuları yetiştirerek bu mali yükten kurtulma düşüncesi ortaya çıkmıştır (Onağ ve Çevik, 2019). $\mathrm{Bu}$ çerçevede bakıldığında kulüplerin altyapılarından oyuncu yetiştirmesinin finansal olarak olumlu katkılar sağlayabileceği söylenebilir. Genç oyunculara yapılacak yatırımların gelecekte yüksek kazançlı geri dönüşlü yatırımlar olduğu açıktır (Sagar, Busch \& Jowett, 2010). Öz kaynak düzeninden yetiştirilip A takımlara monte edilecek futbolcuların, harcanacak transfer bedellerinin kulüp kasasında kalmasını sağlaması ve kendilerinin başka kulüplere transferi halinde ise bonservis ücretlerinden elde edilecek gelirleri kulüplerine kazandırması mümkün olacaktır (Yurtsever, 2015).

Deloitte'un raporunda açıklandığı üzere, Türk futbolunun lokomotifi konumunda olan dört büyük kulübün finansal açıdan kriz içerisinde olduğu açıkça görülmektedir. Bu mali kriz ortamına sürükleninceye kadar altyapılarından yeterli sayıda oyuncuyu A takıma kazandıramadıkları söylenebilir. Ayrıca UEFA'nın şart koştuğu finansal fair play çerçevesinde transferlere getirilen limit kısıtlamalarının futbolda altyapının yeniden önem kazanmasını sağladığı düşünülebilir. Holt (2007), altyapı gelişimini teşvik etmek ve standartları geliştirmek için UEFA'nın rekabeti düzenleyici daimi bir role sahip olduğunu belirtmiştir.

Mevcut problemin daha detaylı ortaya koyulabilmesi için, bu çalışmada Beşiktaş JK futbol takımının son yirmi bir yılda altyapıdan kaç oyuncuya A takımda firsat verdiği, kaç oyuncuyu sürekli olarak A takıma monte edebildiği, altyapıdan A takıma monte edilen oyuncuların istatiksel olarak takıma nasıl bir katkı sağladıkları ve bu yirmi bir yıllık süreçte yabancı transferlere ne kadar harcama yapıldığı tespit edilmeye çalışılmıştır. 


\section{YÖNTEM}

Araştırma modeli: $\mathrm{Bu}$ araştırma, nitel araştırma yöntemlerinden durum çalışması modelinde gerçekleştirilmiştir.

Araştırma örneklemi: Bu çalışmanın örneklemini, kolay ulaşılabilir durum örneklemesi yoluyla belirlenen Beşiktaş JK futbol takımının 1999/2000-2019/2020 sezonları arasındaki 21 sezon oluşturmaktadır.

Verilerin toplanması ve analizi: Veri toplama yöntemi olarak araştırmacı gözlem, görüşme doküman incelemesi ve arşiv kayıtları gibi bir dizi nitel veri toplamı yöntemini problemin doğasına ve kendi beklentilerine göre tek başına veya birlikte kullanabilir (Yıldırım ve Şimşek, 2011: 285). $\mathrm{Bu}$ çalışmada veri toplama yöntemlerinden doküman incelemesi uygulanmıştır. Birçok doküman internetin yaygınlaşmasıyla kamu malı haline gelerek herkes tarafından yazarın izni olmadan ulaşılabilir hale gelmiştir ve bu durum doküman analizinin 'kullanılabilirlik' avantajını sağlamaktadır (Kıral, 2020). Bu avantajdan hareketle, Beşiktaş JK futbol takımının 21 sezon içindeki altyapıdan A takıma dahil olan oyuncu verilerine ulaşmak amacıyla Türkiye Futbol Federasyonu'nun resmi internet sitesi www.tff.org ve transfermarkt.com.tr adl internet sitesinden faydalanılmıştır. Bu amaçla 21 sezonda oynanan 988 maçtaki ilgili veriler Türkiye Futbol Federasyonu'nun resmi internet sitesi www.tff.org adresinden ulaşılarak incelenmiş olup, www.transfermarkt.com.tr adresinden teyit edilmiştir. Bu şekilde verilerin doğruluğu kontrol edilmiştir.

Veriler incelenirken filiz lisansı başka bir kulüpte olup daha sonra Beşiktaş JK futbol takımının altyapısına katılan futbolcular için '2019-2020 Futbol Sezonu İlan Edilmesi Gereken Hususlar' çerçevesinde aşağıdaki maddeler dikkate alınmıştır (Türkiye Futbol Federasyonu, 2021b).

A Takım listesi b bendi gereğince; "A Takım Listesinde yer alacak en az 14 futbolcunun, Türkiye A Milli Futbol Takımında oynama uygunluğuna sahip futbolcu olması zorunludur."

A Takım listesi c bendi gereğince; "Yukarıdaki "b" bendinde bahsi geçen 14 futbolcudan en az 4'ünün 15'inci yaş gününe denk gelen sezon ile - 21 'inci yaş gününe denk gelen sezonlarda kesintili veya kesintisiz en az 3 sezon veya 36 ay kendi kulübünde tescilli olması zorunludur."

Bu çerçevede Türkiye Futbol Federasyonu'nun 2019-2020 futbol sezonu için yayınladığı bu hususlar kriter alınarak, filiz lisansı başka kulüpte olup Beşiktaş JK futbol takımı altyapısına daha sonra katılan futbolcular için, profesyonel olmadan en az 3 sezon ya da 36 ay Beşiktaş JK futbol takımında tescilli olma şartı aranmıştır.

Çalışmada, altyapıdan A Takım kadrosunda yer alan her bir futbolcu için "Oyuncu 1, Oyuncu 2, ..." şeklinde 1999/2000 sezonundan başlayarak kronolojik bir numaralandırma yapılmıştır.

Araştırmada, futbolcuların Süper Lig, Avrupa Kupaları, Türkiye Kupası ve Türkiye Süper Kupası olmak üzere tüm resmi müsabakalardaki istatistikleri değerlendirmeye alınmıştır. 
Çokpartal, C. ve Yenel, F. (2021). Altyapı Organizasyonlarının futbolcu yetiştirme verimliliği üzerine bir inceleme: Beşiktaş JK örneği. Avrasya Spor Bilimleri ve Eğitim Dergisi, 3(1), 96- 108.

\section{BULGULAR}

Tablo 1. 1999/2000 - 2019/2020 sezonları arası altyapıdan Beşiktaş JK futbol A takımı kadrosuna giren oyuncu sayıs1

\begin{tabular}{cccccccccccc}
\hline Kaleci & $\begin{array}{l}\text { Sağ } \\
\text { Bek }\end{array}$ & $\begin{array}{l}\text { Sol } \\
\text { Bek }\end{array}$ & Stoper & $\begin{array}{l}\text { Ön } \\
\text { Libero }\end{array}$ & $\begin{array}{l}\text { Orta } \\
\text { Saha }\end{array}$ & $\begin{array}{l}\text { Merkez } \\
\text { Orta } \\
\text { Saha }\end{array}$ & $\begin{array}{l}\text { Sağ } \\
\text { Kanat }\end{array}$ & $\begin{array}{l}\text { Sol } \\
\text { Kanat }\end{array}$ & $\begin{array}{l}\text { On } \\
\text { Numara }\end{array}$ & Santrafor & Toplam \\
\hline 9 & 5 & 9 & 7 & 5 & 3 & 7 & 3 & 5 & 4 & 12 & 69 \\
\hline
\end{tabular}

Araştırmada yapılan genel değerlendirmede belirtilen 21 sezonda altyapıdan Beşiktaş JK futbol A takımı kadrosunda toplam 69 oyuncuya yer verilmiştir. En çok 12 oyuncu ile santrafor mevkiinden oyuncu şans bulurken, 3 'er oyuncu ile orta saha ve sağ kanat mevkiinden en az sayıda oyuncu tercih edilmiştir.

Tablo 2. 1999/2000 - 2019/2020 sezonları arası altyapıdan Beşiktaş JK futbol A takımı kadrosunda 50 maçtan fazla ilk 11 'de yer alan oyuncu sayısı ve istatistikleri

\begin{tabular}{lcccccccc}
\hline Oyuncu & $\begin{array}{c}\text { Oynadı̆̆ } \\
\text { Sezon } \\
\text { Sayısı }\end{array}$ & Mevki & $\begin{array}{c}\text { Kadroda } \\
\text { Olduğı } \\
\text { Maç } \\
\text { Sayısı }\end{array}$ & $\begin{array}{c}\text { 11'e } \\
\text { Başladı̆̆ı } \\
\text { Maç } \\
\text { Sayısı }\end{array}$ & $\begin{array}{c}\text { Oyuna } \\
\text { Sonradan } \\
\text { Girdiği } \\
\text { Maç } \\
\text { Sayısı }\end{array}$ & $\begin{array}{c}\text { Oynadığı } \\
\text { Dakika }\end{array}$ & Gol & Asist \\
\hline Oyuncu 30 & 11 & Ön Libero & 443 & 204 & 122 & 19515 & 5 & 10 \\
Oyuncu 5 & 5 & Santrafor & 155 & 114 & 29 & 10180 & 30 & 4 \\
Oyuncu 3 & 5 & Ön Libero & 154 & 91 & 41 & 8556 & 6 & 2 \\
Oyuncu 10 & 4 & On Numara & 134 & 78 & 45 & 7311 & 35 & 10 \\
Oyuncu 12 & 6 & Sol Kanat & 126 & 68 & 34 & 5943 & 7 & 11 \\
\hline
\end{tabular}

Araştırmada, Beşiktaş JK futbol takımının 21 sezonda altyapıdan toplam 69 oyuncudan sadece 5 oyuncuyu 50 maçtan fazla ilk 11'de kullandığı tespit edilmiştir. Mevkiler dikkate alındığında hücum, oyuncuları olan oyuncu 5, oyuncu 10 ve oyuncu 12'nin gol ve asist anlamında takıma yeterli katkıda bulunduğu söylenebilir. Bununla birlikte, ön libero mevkiinde yer alan oyuncu 30'un 11 sezonda 443 kez A takım kadrosunda yer alması istikrar açısından göze çarpmaktadır. 
Çokpartal, C. ve Yenel, F. (2021). Altyapı Organizasyonlarının futbolcu yetiştirme verimliliği üzerine bir inceleme: Beşiktaş JK örneği. Avrasya Spor Bilimleri ve Eğitim Dergisi, 3(1), 96- 108.

Tablo 3. 1999/2000 - 2019/2020 sezonları arası altyapıdan Beşiktaş JK futbol A takımı maç kadrosunda 50 maçtan fazla yer alan oyuncu sayısı ve istatistikleri

\begin{tabular}{|c|c|c|c|c|c|c|c|c|}
\hline Oyuncu & $\begin{array}{c}\text { Oynadığı } \\
\text { Sezon } \\
\text { Sayısı }\end{array}$ & Mevki & $\begin{array}{c}\text { Kadroda } \\
\text { Olduğu } \\
\text { Maç } \\
\text { Sayısı }\end{array}$ & $\begin{array}{c}\text { 11'e } \\
\text { Başladığı } \\
\text { Maç } \\
\text { Sayısı }\end{array}$ & $\begin{array}{c}\text { Oyuna } \\
\text { Sonradan } \\
\text { Girdiği } \\
\text { Maç } \\
\text { Sayısı } \\
\end{array}$ & $\begin{array}{c}\text { Oynadığı } \\
\text { Dakika }\end{array}$ & Gol & Asist \\
\hline Oyuncu 30 & 11 & Ön Libero & 443 & 204 & 122 & 19515 & 5 & 10 \\
\hline Oyuncu 5 & 5 & Santrafor & 155 & 114 & 29 & 10180 & 30 & 4 \\
\hline Oyuncu 3 & 5 & Ön Libero & 154 & 91 & 41 & 8556 & 6 & 2 \\
\hline Oyuncu 10 & 4 & On Numara & 134 & 78 & 45 & 7311 & 35 & 10 \\
\hline Oyuncu 12 & 6 & Sol Kanat & 126 & 68 & 34 & 5943 & 7 & 11 \\
\hline Oyuncu 28 & 5 & Stoper & 89 & 29 & 8 & 2744 & 2 & 0 \\
\hline Oyuncu 1 & 3 & Kaleci & 73 & 49 & 4 & 4577 & 0 & 0 \\
\hline Oyuncu 13 & 4 & Stoper & 63 & 41 & 9 & 3717 & 3 & 1 \\
\hline Oyuncu 24 & 4 & Santrafor & 58 & 21 & 31 & 1935 & 11 & 7 \\
\hline Oyuncu 4 & 3 & $\begin{array}{c}\text { Merkez } \\
\text { Orta Saha }\end{array}$ & 54 & 9 & 24 & 982 & 2 & 0 \\
\hline Oyuncu 14 & 4 & Stoper & 53 & 25 & 15 & 2049 & 0 & 0 \\
\hline
\end{tabular}

Araştırmada, Beşiktaş JK futbol takımının altyapısından 21 sezonda sadece 11 oyuncunun 50 maç ve üzeri A takım kadrosunda yer aldığı tespit edilmiştir. Tablo 2'deki hücum oyuncularına ek olarak, santrafor mevkiindeki oyuncu 24, 11 gol 7 asist ile toplam 1935 dakikada takıma katk1 sağlamıştır. Diğer mevkilerdeki oyuncuların pozisyonları gereği takıma oynadıkları dakika çerçevesinde katkı sağladıkları tespit edilmiştir.

Tablo 4. 1999/2000 - 2019/2020 sezonları arası altyapıdan Beşiktaş JK futbol A takımı maç kadrosunda 0-10 maç arası ilk 11'de yer alan oyuncu sayısı ve istatistikleri

\begin{tabular}{cccccccc}
\hline & 0 Maç & 1 Maç & 2 maç & $\begin{array}{c}\mathbf{3 - 1 0} \\
\text { Maç }\end{array}$ & $\begin{array}{c}\text { Toplam } \\
\text { Oyuncu } \\
\text { Sayısı }\end{array}$ & $\begin{array}{c}\text { Oyuncuların } \\
\text { Toplam Gol } \\
\text { Sayısı }\end{array}$ & $\begin{array}{c}\text { Oyuncuların } \\
\text { Toplam Asist } \\
\text { Sayısı }\end{array}$ \\
\hline $\begin{array}{c}\text { Oyuncu } \\
\text { Sayısı }\end{array}$ & 33 & 11 & 7 & 8 & 59 & 12 & 7 \\
\hline
\end{tabular}

Araştırmada toplam 21 sezon incelendiğinde, Beşiktaş JK futbol takımında altyapıdan A takım kadrosuna giren toplam 69 oyuncudan 33'ü hiçbir müsabakada ilk 11'de maça başlamamıştır. 11 oyuncunun sadece 1 maç ilk 11'de görev aldı̆̆, 7 oyuncunun 2 maç ve 8 oyuncunun ise 3-10 maç arası ilk 11 'de şans bulduğu saptanmıştır. 59 oyuncunun toplamda ise takıma 12 gol ve 7 asistlik bir performansla katkı sağladığ 1 belirlenmiştir. 
Çokpartal, C. ve Yenel, F. (2021). Altyapı Organizasyonlarının futbolcu yetiştirme verimliliği üzerine bir inceleme: Beşiktaş JK örneği. Avrasya Spor Bilimleri ve Eğitim Dergisi, 3(1), 96- 108.

Tablo 5. 1999/2000 - 2019/2020 sezonları arası şampiyon olunan sezonlarda altyapıdan Beşiktaş JK futbol A takımı kadrosunda yer alan oyuncu sayısı ve istatistikleri

\begin{tabular}{|c|c|c|c|c|c|c|c|c|}
\hline & Oyuncular & Mevki & $\begin{array}{l}\text { Kadrodaki } \\
\text { Maç Sayısı }\end{array}$ & $\begin{array}{c}\text { İlk } 11 \\
\text { Maç } \\
\text { Sayısı }\end{array}$ & $\begin{array}{c}\text { Sonradan } \\
\text { Oyuna } \\
\text { Girilen } \\
\text { Maç } \\
\end{array}$ & $\begin{array}{l}\text { Oynadı̆̆ı } \\
\text { Dakika }\end{array}$ & Gol & Asist \\
\hline \multirow{3}{*}{$\begin{array}{l}2002 / \\
2003\end{array}$} & \multirow{3}{*}{$\begin{array}{c}\text { Oyuncu } 3 \\
\text { Oyuncu } 8 \\
\text { Oyuncu } 10\end{array}$} & \multirow{3}{*}{$\begin{array}{c}\text { Ön libero } \\
\text { Santrafor } \\
\text { On Numara }\end{array}$} & 39 & 23 & 13 & 2338 & 2 & 0 \\
\hline & & & 13 & 1 & 4 & 158 & 4 & 0 \\
\hline & & & 38 & 28 & 10 & 2533 & 12 & 0 \\
\hline \multirow{3}{*}{$\begin{array}{l}2008 / \\
2009\end{array}$} & Oyuncu 12 & Sol Kanat & 37 & 20 & 14 & 1735 & 4 & 3 \\
\hline & Oyuncu 24 & Santrafor & 19 & 15 & 4 & 1236 & 9 & 3 \\
\hline & Oyuncu 27 & Kaleci & 1 & 0 & 0 & 0 & 0 & 0 \\
\hline \multirow{5}{*}{$\begin{array}{l}2015 / \\
2016\end{array}$} & Oyuncu 30 & Ön libero & 48 & 19 & 24 & 2126 & 1 & 0 \\
\hline & Oyuncu 50 & Kaleci & 4 & 0 & 0 & 0 & 0 & 0 \\
\hline & Oyuncu 51 & Stoper & 1 & 1 & 0 & 90 & 0 & 0 \\
\hline & Oyuncu 52 & Sağ Bek & 2 & 0 & 1 & 28 & 0 & 0 \\
\hline & Oyuncu 53 & Santrafor & 2 & 0 & 2 & 32 & 0 & 0 \\
\hline \multirow{6}{*}{$\begin{array}{l}2016 / \\
2017\end{array}$} & Oyuncu 28 & Stoper & 35 & 14 & 2 & 1284 & 1 & 0 \\
\hline & Oyuncu 30 & Önlibero & 40 & 11 & 16 & 1254 & 0 & 0 \\
\hline & Oyuncu 50 & Kaleci & 2 & 0 & 0 & 0 & 0 & 0 \\
\hline & Oyuncu 53 & Santrafor & 4 & 0 & 2 & 52 & 0 & 0 \\
\hline & Oyuncu 54 & Sol Bek & 2 & 0 & 1 & 5 & 0 & 0 \\
\hline & Oyuncu 55 & Sol Kanat & 6 & 2 & 0 & 161 & 1 & 0 \\
\hline
\end{tabular}

Araştırmada toplam 21 sezon içinden Beşiktaş JK futbol takımının şampiyon olduğu 4 sezon incelendiğinde, 2002/2003 sezonunda oyuncu 3 ile oyuncu 10'nun oynadı̆̆ dakikalar ve sayısal istatistikleri göz önüne alındığında A takım kadrosuna monte edilerek verim elde edildiği söylenebilir. 2008/2009 sezonunda ise, oyuncu 12 ile oyuncu 24'ten oynadıkları dakika, gol ve asist anlamında katkı alındığı belirlenmiştir. 2015/2016 sezonunda sadece oyuncu 30'tan ve 2016/2017 sezonunda ise oyuncu 28 ve 30’tan önemli ölçüde verim alındığ 1 tespit edilmiştir.

Tablo 6. $1999 / 2000$ - 2019/2020 sezonları arası Beşiktaş JK futbol takımı altyapısından yetişen oyunculardan elde edilen transfer gelirleri

\begin{tabular}{cccccccccccc} 
Oyuncular & $\mathbf{5}$ & $\mathbf{8}$ & $\mathbf{1 0}$ & $\mathbf{2 4}$ & $\mathbf{2 5}$ & $\mathbf{2 7}$ & $\mathbf{2 8}$ & $\mathbf{3 1}$ & $\mathbf{3 4}$ & $\mathbf{3 9}$ & $\mathbf{4 1}$ \\
\hline Transfer & 5 & 200 & 5 & 2.1 & 120 & 90 & 6 & 75 & 100 & 425 & 50 \\
Gelirleri & $\begin{array}{c}\text { milyon } \\
\text { bin }\end{array}$ & milyon & milyon & bin & bin & milyon & bin & bin & bin & bin \\
& $(\mathrm{S})$ & $(\mathrm{K})$ & $(\mathrm{S})$ & $(\mathrm{S})$ & $(\mathrm{K})$ & $(\mathrm{K})$ & $(\mathrm{S})$ & $(\mathrm{K})$ & $(\mathrm{K})$ & $(\mathrm{S})$ & $(\mathrm{K})$ \\
\hline
\end{tabular}

Not: Para biri Avro cinsinden olup (S) satışı, $(K)$ ise kiralığ ifade etmektedir.

Araştırmada incelenen 21 sezonda, altyapıdan yetişen 11 oyuncudan toplam 19 milyon 160 bin Avro transfer geliri elde edildiği saptanmıştır. Satışlar incelendiğinde, oyuncu 5 'ten 5 milyon Avro, oyuncu 10'dan 5 milyon Avro, oyuncu 24'ten 2.1 milyon Avro, oyuncu 28'den 6 milyon 
Çokpartal, C. ve Yenel, F. (2021). Altyapı Organizasyonlarının futbolcu yetiştirme verimliliği üzerine bir inceleme: Beşiktaş JK örneği. Avrasya Spor Bilimleri ve Eğitim Dergisi, 3(1), 96- 108.

Avro ve oyuncu 39'dan 425 bin Avro olmak üzere toplam 18 milyon 525 bin Avro gelir elde edilmiştir. Diğer 6 oyuncudan ise 635 bin Avro kiralama geliri sağlandığı belirlenmiştir.

Tablo 7. 1999/2000 - 2019/2020 sezonları arası Beşiktaş JK futbol takımına transfer edilen yabancı oyuncu sayıları ve transfer harcamaları

\section{Transfer Edilen Yabancı Oyuncu Sayısı Yabancı Oyuncular İçin Harcanan Transfer} Bedelleri

Araştırma çerçevesinde, 1999/2000 - 2019/2020 sezonları arasını kapsayan 21 sezonda toplam 104 yabancı futbolcunun Beşiktaş JK futbol takımına transfer edildiği belirlenmiştir. Yapılan yabancı oyuncu transferleri için toplamda 177 milyon 530 bin Avro transfer bedeli ödendiği tespit edilmiştir.

\section{TARTIŞMA}

Araştırmada Beşiktaş JK futbol takımının 1999/2000 - 2019/2020 yılları arasındaki toplam 21 sezonda altyapıdan A takım kadrosuna dahil edilen oyuncuların sayıları ve istatistikleri incelenmiştir.

Bu çerçevede 21 sezonda, 12'si santrafor mevkiinde olmak üzere toplam 69 oyuncunun A takım kadrosunda şans bulduğu tespit edilmiştir. Dağılıma bakıldığında, sezon ortalaması olarak altyapıdan 3 oyuncunun A takım kadrosunda yer bulduğu söylenebilir. Ancak veriler daha detaylı incelendiğinde, 50 maç ve üzeri ilk 11'de yer bulan oyuncu sayısı sadece 5 futbolcu ile sınırlı kalmıştır. Bu 5 futbolcunun istatistiksel verileri incelendiğinde oyunda kalma süresi, gol ve asist anlamında takıma katkı sağladıkları söylenebilir. Bu durum altyapıdan oyunculara firsat verildiğinde, bu futbolculardan verim alınabileceğini göstermektedir. Bununla beraber 50 maç ve üzeri kadroda şans bulan oyuncu sayısı ise 11 futbolcu olarak belirlenmiş̧ir.

İlk 11'de 0-10 maç aralığında yer alan oyuncu sayısı incelendiğinde, bu aralıkta 59 oyuncu tespit edilmiştir. Bu 59 oyuncudan, 33 futbolcu ilk 11'de hiç yer bulamazken 11 futbolcu sadece $1 \mathrm{kez}$ ilk 11'de oynama firsatı yakalamıştır. Ayrıca bu oyuncuların kadroya girdikleri ya da ilk 11 'de firsat yakaladıkları resmi maçların genellikle Türkiye Kupası müsabakaları oldukları saptanmıştır. Türkiye Kupası'nın prestiji Süper Lig'e oranla daha düşük görüldüğü için altyapı oyuncularına kupa platformunda şans verilmiştir. Mevcut durum altyapıdan oyuncuların A takım kadrosunda tercih edilmediğini kanıtlar niteliktedir. Aslan vd. (2015), çalışmalarında altyapılardan futbolcuların yetişmemesinden ziyade, A takım kadrosuna dahil edilen oyuncuların yeterince oynama süresi bulamamasının sorun teşkil ettiğini belirtmektedirler. 
İncelenen 21 sezonda Beşiktaş JK futbol takımı 4 kez Süper Lig şampiyonu olmuştur. 2002/2003 sezonunda 3, 2008/2009 sezonunda 2 futbolcudan mevkilerine göre yeterli verim alındığ söylenebilir. 2015/2016 ve 2016/2017 sezonlarında ise sadece ön libero mevkiindeki Oyuncu 30 'tan oynama süresi bakımından verim alındığı söylenebilir. Bu durum altyapı oyuncularına daha fazla firsat verildiğinde, şampiyonluğa giden yolda takımlarına katkı verebileceklerini göstermektedir. Altyapıdan yetiştirilen öz kaynak oyuncularının takıma monte edilmesi takıma bağl1lık seviyesini artırarak şampiyonluk yolunda motivasyonu yükseltebilir (Fanatik, 2021).

Araştırmada 21 sezon içinde, altyapıdan yetişen 11 oyuncunun satılık ve kiralık bedellerinden 19 milyon 160 bin Avro gelir elde edildiği tespit edilmiştir. Özellikle Oyuncu 5, Oyuncu 10, Oyuncu 24 ve Oyuncu 28'in satışından 18 milyon 100 bin Avro gelir elde edilmiştir. Beşiktaş JK futbol takımı bu oyunculardan hem sportif hem de finansal açıdan verim almıştır. Bu durum altyapının futbol takımlarının mali ve finansal başarısındaki önemini vurgulamaktadır. Akkoyun (2014) araştırmasında, yapılacak altyapı yatırımlarının bilimsel metotlar izlendiği takdirde sportif ve mali başarıyı beraberinde getireceğini ortaya koymuştur. Ayrıca kronolojik oyuncu numaralandırılmasından görüldügü üzere, bu oyuncuların incelenen 21 sezonun ilk dilimlerinde olduğu ve son dönemlerde altyapıdan mali ve sportif anlamda yeterli katkının alınmadığı anlaşılmaktadır. Ancak talepler ve kaynaklar doğrultusunda altyapı organizasyonlarında uygulanacak proaktif müdahale programları genç oyuncuların gelişimi ile kulüplerin finansal başarısı ve saygınlığı hususunda faydalı olabilir (Morris, Tod, \& Oliver, 2015).

$\mathrm{Bu}$ çalışmada, araştırmaya konu olan 21 sezonda Beşiktaş JK futbol takımının 104 yabancı futbolcuya toplam 177 milyon 530 bin Avro transfer ücreti ödediği tespit edilmiştir. Bu durum altyapıdan oyuncu kullanmak yerine yabancı oyuncu transferinin tercih edildiğini göstermektedir. Ayrıca yabancı transferlerin mali açıdan kulübe büyük külfet olduğu söylenebilir. Kulüplerin kadro oluştururken yabancı oyuncuları tercih etmeleri, altyapıdan yetişecek Türk futbolcuların A takım kadrosunda firsat bulmalarını olumsuz etkilemekle birlikte ödenecek yüksek transfer meblağları kulüplerin ekonomilerine zarar verecektir (Yüce, Katırcı ve Kuzu, 2017).

\section{SONUÇ VE ÖNERILER}

Futbol kulüplerinin sportif ve mali başarıyla birlikte varlıklarını sürdürebilmek adına sağlam temeller üzerine kurulu altyapı organizasyonlarına ihtiyacı olduğu görülmektedir. Bu anlamda kulüp lisans sisteminin uygulanmasıyla UEFA'nın amacı, altyapı organizasyonlarına yapılacak yatırımlar gibi kritik öneme sahip bir dizi uygulamanın kulüplerin uzun dönemde varlıklarını sürdürebilmesi için kulüpler tarafından hayata geçirilmesidir (Ducrey, Ferreira, Huerta, \& Marston, 2003). Sağlam altyapısı olan kulüpler ayakta kalmaya devam edecek, altyapısı işlemeyen kulüpler çökmeye mecbur kalacaklardır (Akkoyun, 2014). Bu anlamda futbol altyapılarının önemi açıkça ortadadır. Beşiktaş JK futbol kulübünün, son 21 yıl içinde belli dönemler dışında altyapıya yeteri önemi göstermediği söylenebilir. Özellikle son yıllarda mali krizin artmasıyla birlikte altyapıdan hem sportif hem de mali açıdan yeterli verim elde edilememesi daha büyük sorun teşkil 
etmiş̧tir. $\mathrm{Bu}$ gerçekler doğrultusunda, Beşiktaş JK harekete geçerek yeni bir altyap1 oluşturulmasının temellerini atmaya başlamıştır. Beşiktaş JK Başkanı Ahmet Nur Çebi, ekonomik çıkış yolu olarak altyapıdan yetişen oyuncuların satışından elde edilecek gelirlerin kulüp bütçesi için önemini vurgulamıştır (Goal, 2021b). Ayrıca, Başkan Çebi bu öze dönüş hamlesiyle birlikte A takımda oynayabilecek yetenekli, başarı arzulayan, ucuz ve iyi ahlaklı gençlerden oluşan bir kadro kurmak istediklerini belirtmiştir (Karakartal, 2021). Beşiktaş JK'nın mevcut sorunu içselleştirerek yaptı̆ğ altyapı atılımları hem kulüp hem de Türk futbolunun geleceği için umut vericidir.

Sonuç olarak, başta kulüpler olmak üzere Türk futbolu içindeki tüm paydaşlar altyapıya olan bakış açılarını değiştirmeli ve kulüplerin sürdürülebilirliği için önemli olan altyapıya yeterli düzeyde yatırımlar yapılarak profesyonel kadrolarca organizasyonu sağlanmalıdır. Bu çalışma sadece Beşiktaş JK ile sınırlandırıldığı için, diğer kulüplerin altyapı verimliliği üzerine yapılacak çalışmalar konunun daha iyi anlaşılması açısından literatüre katkı sağlayacaktır.

Çıkar Çatışması: Herhangi bir çıkar çatışması mevcut değildir.

Yayın Etiği: Mevcut çalışmanın yazım sürecinde "Yükseköğretim Kurumları Bilimsel Araştırma ve Yayın Etĭgi Yönergesi" kapsamında bilimsel, etik ve alıntı kurallarına uyulmuş olup; toplanan veriler üzerinde herhangi bir tahrifat yapılmamış ve bu çalışma herhangi başka bir akademik yayın ortamına değerlendirme için gönderilmemiştir.

\section{KAYNAKÇALAR}

Akkoyun, S. (2014). Türkiye'deki futbol kulüplerinin alt yapılarının yapılanması, yönetim biçimleri, idari yapısı ve Avrupa'daki örneklerle kıyaslanması. Yayımlanmamış Yüksek lisans tezi, İstanbul Kültür Üniversitesi, Sosyal Bilimler Enstitüsü, Spor İktisat Anabilim Dalı, İstanbul.

Aslan, C. S., Akça, F. ve Müniroğlu, S. (2015). Süper Lig futbol takımlarının altyapılarından oyuncu yetiştirme verimliliklerinin incelenmesi. Spormetre Beden Eğitimi ve Spor Bilimleri Dergisi, 13(2), 103-112.

Bonifance, P. (2007). Futbol ve küreselleşme. İstanbul: NTV Yayınları.

Deloitte. (2021). https://www2.deloitte.com/content/dam/Deloitte/tr/Documents/technology-mediatelecommunications/2021e-baslarken-avrupada-ve-turkiyede-futbol-ekonomisi.pdf, Erişim tarihi: 6 Mayıs 2021.

Ducrey, P., Ferreira, C., Huerta, G. \& Marston, K. (2003). UEFA and Football Governance: A new model. Neuchâtel: Centre international d'étude du sport.

Fanatik. (2021). https://www.fanatik.com.tr/altyapi-sistemi-nedir-altyapi-takimi-nasil-olusur-hangi-yas-gruplarinikapsar-2204112, Erişim tarihi: 8 Mayıs 2021.

Goal. (2021a). https://www.goal.com/tr/galeri-listesi/sueper-lig-tarihinin-en-pahali-50transferi/qng2twsxy7cp1gptmw2khewgl, Erişim tarihi: 5 Mayıs 2021.

Goal. (2021b). https://www.goal.com/tr/haber/ahmet-nur-cebi-tek-cikis-yolu-altyapiya-daha-fazlaoenem/1ajhup2fd96mg1oz75nlkdtvry, Erişim tarihi: 8 Mayıs 2021. 
Çokpartal, C. ve Yenel, F. (2021). Altyapı Organizasyonlarının futbolcu yetiştirme verimliliği üzerine bir inceleme: Beşiktaş JK örneği. Avrasya Spor Bilimleri ve Eğitim Dergisi, 3(1), 96- 108.

Holt, M. (2007). The ownership and control of elite club competition in European football. Soccer \& society, 8(1), 50-67.

Hünerli, S. (2014). Türkiye'de futbol iktidarı ve fanatizmin medyadaki karikatürlerde yansıması. (Ed. Volkan Ekin), Türkiye'de spor ve medya içinde (s:321-341). İstanbul: Köprü Kitapları.

Karakartal. (2021). https://www.karakartal.com/futbol/ahmet-nur-cebiSXGLQ4232SXQ?sira=4, Erişim tarihi: 8 Mayis 2021.

Katırcı, H. (2019). Spor endüstrisi ve ekonomisi. (Ed. Nilgün Çağlarırmak Uslu), Spor ekonomisi içinde (s:2-21). Eskişehir: Anadolu Üniversitesi.

Kıral, B. (2020). Nitel bir veri analizi yöntemi olarak doküman analizi. Siirt Üniversitesi Sosyal Bilimler Enstitüsü Dergisi, 8(15), 170-189.

Morris, R., Tod, D. \& Oliver, E. (2015). An analysis of organizational structure and transition outcomes in the youthto-senior professional soccer transition. Journal of applied sport psychology, 27(2), 216-234.

Onağ, Z. ve Çevik, S. (2019). Türkiye'de altyapıdan futbolcu yetişememesinin nedenleri ve çözüm önerileri üzerine nitel bir araştırma. $C B \ddot{U}$ Beden Eğitimi ve Spor Bilimleri Dergisi, 14(2), 326-343. DOI: $10.33459 /$ cbubesbd.637214.

Sagar, S. S., Busch, B. K., \& Jowett, S. (2010). Success and failure, fear of failure, and coping responses of adolescent academy football players. Journal of Applied Sport Psychology, 22(2), 213-230.

TKYD. (2009). Kurumsal Yönetim İlkeleri Işı̆ğında' Türk futbol kulüpleri yönetim rehberi. İstanbul: Türkiye Kurumsal Yönetim Derneği.

Yıldırım, A. ve Şimşek, H. (2011). Sosyal bilimlerde nitel araştırma yöntemleri. Ankara: Seçkin Yayıncılık.

Yurtsever, G. (2015). Transfer bugün altyap1 ise gelecektir. 14.07.2015, http://www.futbolekonomi.com/index.php/haberler-makaleler/genel/290-gurdogayurtsever/3642transfer.html.

Türkiye Futbol Federasyonu. (2021a). https://www.tff.org/default.aspx?pageID=294, Erişim tarihi: 5 Mayıs 2021

Türkiye Futbol Federasyonu. (2021b). https://www.tff.org/Resources/TFF/Documents/TFF/Lisanslama/2019-2020ilan-edilmesi-gereken-hususlar.pdf, Erişim tarihi: 7 Mayıs 2021.

Yenel, İ.F. ve Parasız, Ö. (2019). Türk spor yönetimi. (Ed. A. Azmi Yetim), Yönetim ve spor içinde (s:307-372). Ankara: Gazi Kitabevi.

Yüce, A., Katırcı, H. ve Kuzu, C. (2017). Türk futbolunda yabancı futbolcu sınırlaması ve Türk futbolcuların görüşleri. CBÜ Beden Eğitimi ve Spor Bilimleri Dergisi, 12(2), 24-39. 


\section{EXTENDED ENGLISH SUMMARY}

\section{A Study on Efficiency of Youth Academy Organizations in Raising Players: Sample of Beşiktaş JK}

\section{Introduction}

With the millennium age, football has become a global phenomenon followed by all crowds. There is no more global phenomenon than an uninhibited football empire that is popular and exhilarates people (Bonifance, 2006:9). UEFA Champions League, which started to be played in 1992 and generated an important economic market, turned football clubs not only into a sportive organization but also into economic organizations (TKYD, 2009:14). Transfers are one of the significant factor of this huge football market (Katırc1, 2019:13). Football clubs in Turkey have spent a great deal of money on transfers in order to get a share from the mentioned economic market and to achieve sportive success. While the most expensive 50 transfers of the Turkish Super League was investigated, Fenerbahçe, Galatasaray, Beşiktaş JK and Trabzonspor spent a total of 401 million Euros for these transfers, most of which were foreign players (Goal, 2021). However, the expected economic contribution and sportive efficiency from these transfers could not be achieved due to sporting failures, adaptation problems and injuries. As a result, huge amount of transfer expenditures has become one of the reasons of the financial crisis that clubs are trying to struggle with. According to the Deloitte report published in 2021, total debt of 4 big clubs peaked in 2020 and exceeded 13 billion TL. This crisis environment has encouraged clubs to plan their future regarding their own resources, in other words youth academies. It can be argued that these big clubs could not bring enough players to the first team from their youth academies until they were dragged into financial crisis. In this study, the efficiency of Beşiktaş JK youth academy in raising players will be examined in order to reveal the current problem in detail.

\section{Method}

The research was carried out using case study model and document analysis method. Totally 21 seasons between 1999/2000 and 2019/2020 including 988 matches were analyzed. The official website of the Turkish Football Federation, www.tff.org and transfermarkt.com.tr have been used for the analysis.

\section{Findings}

Obtained data demonstrates that Beşiktaş football club included 69 players in first team squad from youth academy in total when 21 seasons were examined. It was found out that 5 of these 69 players had chance to appear in line up of the matches 50 times or more whereas 33 of them had no appearance in line up of the matches. Contribution of these 5 players to the team in terms of goal, asist and duration of appearance is obviously seen. Moreover, it was determined that the club earned 18 million 100 thousand Euros transfer income from 4 of these players while 177 million 530 thousand Euros was paid for foreign players in the same 21 seasons. 


\section{Discussion and Conclusion}

It was discovered that 69 players from youth Academy had chance to appear in the first team squad. The number of players appeared in line up of the matches 50 times or more is 5 . Contribution of these 5 players to the team in terms of goal, asist and duration of appearance is statistically obvious and it demonstrates that efficiency can be obtained from young players when an opportunity is given. On the other hand, 33 of them had no appearance in line up of the matches and 11 of them had only one chance mostly in Turkish Cup matches which have relatively less prestige than league matches. This situation proves that the players from the youth academy are not preferred in the first team squad. Moreover, it was determined that in 21 seasons, 19 million 160 thousand Euros of income was earned from the sales and rental prices of 11 players from the youth academy. Beşiktaş football team benefited from these players both in terms of sportive and financial contributions. This highlights the importance of youth academies in terms of sportive and financial success of football teams. Eventually, it can be put forward that football clubs needs organized youth academies to maintain their existence and regarding this, Beşiktaş football club has not given enough importance to the youth academy except for certain periods in the last 21 years. Especially in recent years, with the increase of the financial crisis, the inability to obtain enough efficiency from the youth academy both in terms of sports and finance has caused a bigger problem. Given these realities, Beşiktaş club has taken action and started to lay the foundations of a new youth academy organization. These attempts can be considered as encouraging for future of the club and Turkish football.

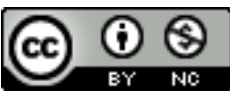

Bu eser Creative Commons Atıf-Gayri Ticari 4.0 Uluslararası Lisansı ile lisanslanmıştır. 